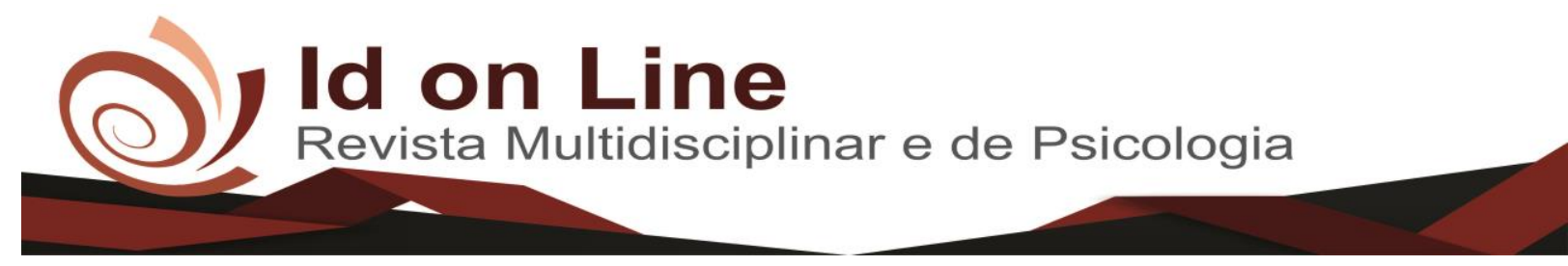

Artigo de Revisão

\title{
O Papel da Auditoria Interna na Detecção de Fraudes e Erros em Iniciativas Privadas
}

\author{
Cliciana da Silva Correia Freitas ${ }^{1}$; Ramon Amorim Sena ${ }^{2}$
}

\begin{abstract}
Resumo: O estudo tem como objetivo geral analisar o papel da auditoria interna, como agente anti-irregularidade. Já especificamente visou: Buscar na literatura a importância da auditoria interna em agregar valores de probidade administrativa, analisar contribuições prestadas pela auditoria interna e investigar as diferenças entre fraudes e erros cometidos no âmbito interno. Trata-se de um estudo de natureza básica, com um procedimento exploratório, realizado no município de Icó - CE, entre os meses de agosto a outubro de 2018. Utilizou-se de um levantamento sobre o tema abordado por meio da base de dados scielo, livros sobre auditoria e normas do Conselho Federal de Contabilidade. Para seleção das fontes, foram considerados os seguintes descritores de inclusão: a auditoria interna, erros e fraudes e a temática abordada, e para exclusão: Artigos que fugiram da linha de pesquisa e artigos considerados repetidos em relação à temática. Foi considerado o período de 2014 a 2018 , baseado em pesquisa em site de revistas especializadas e na biblioteca Professor Paulo Petrola da Faculdade Vale do Salgado - FVS. A pesquisa foi considerada satisfatória, com relação à temática abordada.
\end{abstract}

Palavras-chave: Auditoria Interna. Erros. Fraude.

\section{The Role of Internal Audit in Detection of Frauds and Errors in Private Initiatives}

\begin{abstract}
The study aims to analyze the role of internal audit as an anti-irregularity agent. Specifically, it aimed to: Search the literature for the importance of internal auditing in aggregating values of administrative probity, analyzing contributions made by internal auditing, and Investigating the differences between $i$ fraud and errors. This is of nature basic, with an exploratory procedure, carried out in the municipality of Icó - CE, between August and October of 2018. A survey was carried out on the topic addressed through the scielo database, books on auditing and standards of the Federal Accounting Council. In order to select the sources, the following inclusion descriptors were considered: internal audit, errors and frauds, and the topic addressed, and for exclusion: Articles that fled the line of research and articles considered repeated in relation to the theme. It was considered the period from 2014 to 2018, based on research on the site of specialized and in the library of Teacher Paulo Petrola's at the Faculdade Vale do Salgado-FVS. The research was considered satisfactory, in relation to the subject matter.
\end{abstract}

Keyworlds: Internal audit. Errors. Fraud.

\footnotetext{
${ }^{1}$ Graduanda do curso de bacharelado em Ciências Contábeis da Faculdade Vale do Salgado (FVS).

E-mail: cliceana@hotmail.com

${ }^{2}$ Especialista em Auditoria, Controladoria, e Gestão Financeira pela Faculdade Católica Rainha do Sertão. Professor do curso de Ciências Contábeis da Faculdade Vale do Salgado (FVS). E-mail: ramon@acesfcontabil.com.br
} 


\section{Introdução}

Diante do atual crescimento das iniciativas privadas, o auditor interno se tornou fundamental e indispensável nas organizações na detecção de irregularidades com exames minuciosos das demonstrações contábeis apresentadas pelo controle interno, com o dever de cumprir as exigências das normas cabíveis, para a eficiência e credibilidade da organização como um todo (ALVES et al., 2017).

Com os esquemas de corrupção explicitamente demonstrados nos meios midiáticos e sociais envolvendo empresas privadas em consonância com o Governo Federal, a esfera empresarial começou a recrudescer os planejamentos que frisam a inviolabilidade administrativa e a implementá-los, de forma que os investidores obtenham confiança naquilo que investem. Dentre essas estratégias anti-improbidade, é notória a importância e o papel do auditor interno no controle de fraudes e erros (ALESSI, 2017).

A atuação do auditor interno não foi pensada como exclusiva para detectar corruptibilidades e/ou erros, mas, para harmonizar o trabalho de forma que as funções de cada um dos que compõem a equipe da empresa, tenham suas atribuições concretizadas dentro do que requerem as regras de bom funcionamento organizacional. Entretanto, as prioridades do mercado exigem uma mudança de esquema, pois o que antes era apenas mais uma atribuição do auditor tornou-se uma real prioridade: evitar irregularidades com o fito de dar crédito e confiabilidade ao escopo de investidores (SILVA et al., 2014).

Com isso, observa-se a imprescindibilidade do desenvolvimento de auditoria focado, além da qualidade do serviço prestado, numa ação que seja um filtro que separe as informações fidedignas dentro das companhias financeiras, ou seja, ressalte a positividade dos trabalhos exitosos, e ao identificar alguma ação que prejudique a companhia, essa informação deve ser repassada à administração para que puna, através de sanções internas, erros ou fraudes que tragam desconfiança aos investidores ou que prejudiquem o enredo de prosperidade financeira alcançada em seus investimentos (CARVALHO; VIEIRA, 2015).

Assim, o presente estudo tem em sua principal inspiração demonstrar de forma clara a importância do trabalho desempenhado pelo auditor interno dentro das organizações, gerando uma maior confiabilidade para o escopo organizacional, tendo em vista essa importância não só para a área interna, mas também para o público externo (FREITAS, 2014).

As entidades se deparam com vários obstáculos ao longo do seu desenvolvimento, entre eles a ocorrência de fraudes e erros que prejudicam a iniciativa privada a alcançar os objetivos almejados. Diante disso, surgiu a necessidade de um profissional que auxilie os gestores na 
supervisão das atividades. Portanto, a auditoria interna é essencial à entidade, e busca auxiliar a gestão com orientações e sugestões, dando um direcionamento aos trabalhos, colaborando como uma espécie de assessoria à gestão. Surge, portanto, a seguinte questão: qual a importância do auditor interno no processo de detecção de fraudes e irregularidades?

Este estudo teve como objetivo geral analisar o papel da auditoria interna, como agente anti-irregularidade. Em termos específicos visou: buscar na literatura a importância da auditoria interna em agregar valores de probidade administrativa, analisar contribuições que possam ser prestadas pela auditoria interna em iniciativa privada e investigar as diferenças entre fraudes e erros cometidos no âmbito interno.

A pesquisa externa relevância aos meios sociais, por trazer a tona à discussão de uma forma social e de promoção às atividades anticorrupção que previnam improbidades internas; acadêmicos, por colaborar com pesquisas de estudantes universitários que trabalhem com a mesma linha de pesquisa; e, científicos: no que tange às pesquisas de âmbito nacional utilizadas para o escopo do trabalho, bem como a metodologia embasada nessa pesquisa de cunho integrativo.

\section{A Relação da Contabilidade e a Auditoria, Conceituação e Objetivos da Auditoria Interna}

A contabilidade é uma ciência social, que visa à proteção de um conjunto de elementos que compõem o patrimônio das entidades, assim como também é uma fornecedora de informações da situação econômica e financeira da organização. Diante da tamanha importância destas demonstrações, percebeu-se por parte dos investidores financeiros a necessidade de um profissional que não tivesse vínculos empregatícios com a empresa para comprovar a situação real das demonstrações contábeis (GABRIEL, 2018).

Como consequência da necessidade desta verificação geral, surgiu o profissional auditor independente que efetua seu trabalho sem qualquer ligação trabalhista com a entidade. Este profissional desenvolve suas atividades totalmente interligadas com as práticas contábeis e com a utilização de normas contábeis estabelecidas por órgãos competentes que regulam a profissão do contador no Brasil. Assim como também, levando em conta as exigências do mercado, surgiu o auditor interno como ramificação da auditoria externa, o auditor interno é um funcionário da empresa e é o foco principal desta pesquisa (BLANCH, 2016).

Auditoria interna é uma atividade de avaliação independente, que consiste no assessoramento à administração, voltada para o levantamento, estudo e avaliação das 
demonstrações contábeis e registros administrativos, contribuindo com a eficiência, eficácia, legalidade, e efetividade da organização e do controle interno (CREPALDI, 2004).

Os objetivos do auditor interno é examinar os dados fornecidos pelo controle interno e comprovar sua eficiência e eficácia, observar o cumprimento de leis e normas internas, trazer proteção aos bens da entidade, diminuir indícios de irregularidades e perda financeiras, assim como, formular um parecer sobre a situação em que se encontra a empresa. Diminuindo dessa forma, os indicadores de irregularidades, práticas estas que acabam manchando a integridade da empresa diante de possíveis investidores (MOALLEM, 2016).

Diante disso, entende-se a importância que a contabilidade exerce sobre o trabalho do auditor e a relevância que possui a análise feita por esse profissional nas informações colhidas, fortalecendo e resguardando a integridade da empresa com recomendações de melhoria dos departamentos, para por fim alcançar os objetivos traçados pela entidade com segurança e eficiência ajudando-a a alcançar suas metas.

\section{O Papel do Auditor Interno em Agregar Valor à Organização}

O auditor trabalha em conjunto com a administração da empresa, avaliando os controles internos e buscando sempre diminuir os riscos que podem prejudicar tanto empresários como consumidores, pois se de fato forem comprovados prejuízos, eles certamente serão repassados ao consumidor por meio de seus produtos (SILVA; LOPES; BARBOSA, 2017).

O profissional auditor interno se tornou uma peça fundamental nas organizações pelo fato de contribuir com a eficiência, eficácia, legalidade, e efetividade da organização, através de rigorosas fiscalizações exercidas por meio de suas técnicas que comprove a qualidade do controle interno, diminuindo dessa forma os indicadores de Irregularidades, práticas essas que acabam manchando a integridade da empresa diante da população e de possíveis investidores (SILVA et al., 2014).

$\mathrm{O}$ auditor interno trabalha para trazer conformidade das normas internas e proteção aos bens da entidade, sempre dentro dos padrões das normas e legislações vigentes, diminuindo indícios de irregularidades e perdas financeiras. Além de contribuir com recomendações de melhorias e aprimoramento dos sistemas de controle interno, contribuindo para uma boa administração (GOMES, 2015).

A atividade prestada pela auditoria interna agrega valor ao desempenho da empresa, o relatório elaborado por esse profissional é de grande importância para a empresa nas tomadas 
de decisões, trazendo credibilidade e confiança junto às financiadoras, investidores e fornecedores, abrindo desta forma portas para o crescimento da entidade e tanto funcionários como administradores são beneficiados com esse crescimento (ALVES; TIOSSI; MILAN, 2016).

Dessa forma, o auditor funciona como uma ferramenta de controle e prevenção de ilícitos sobre as informações, se destacando como uma peça fundamental, contribuído e forma eficiente para o alcance dos objetivos e visão da gestão.

\section{Responsabilidade pela Prevenção e Detecção da Fraude e Erro}

Segundo as Normas Brasileiras de Contabilidade, o auditor interno "não é responsável e nem pode ser responsabilizado pela prevenção de fraudes ou erros". No entanto, o seu trabalho deve ser planejado de forma preventiva, analisando a probabilidade de detectar erros ou fraudes dentro da organização empresarial que prejudique a exatidão das demonstrações contábeis (SILVA, 2017).

Os gestores da entidade têm a responsabilidade primária na detecção e prevenção de informes nas demonstrações contábeis, por isso é de grande importância haver uma comunicação clara entre os responsáveis pela administração e o auditor, facilitando a descoberta de fraudes (JUSTINO; SILVA, 2016).

Diante dos riscos, é feita uma análise pelo auditor através de informações repassadas pelo controle interno específico, ficando evidente que mesmo diante dessa prevenção não são eliminados totalmente os riscos de irregularidades, podendo ainda ocorrer tal fato na organização (MONTEIRO, 2015).

O auditor tem o dever de deixar a parte administrativa da organização sempre informada por escrito de toda e qualquer irregularidade observada na empresa, e sugerindo medidas por parte do gerenciamento. Caso seja encontrados desvios das normas internas, essa informação deve ser repassada, a quem de fato solicitou o trabalho, informando ao solicitante efeito em seu relatório caso as medidas corretivas não sejam atendidas, para isso, o auditor deve fazer uma averiguação de probidade em todos os departamentos da entidade, verificando o seu desempenho e cumprimento de leis e das normas internas (ROCHA, 2016).

É fundamental a implantação de sistema de controle interno eficiente para averiguar informes e suas dimensões em todos os departamentos da entidade, ficando claro que a 
responsabilidade pelo controle interno é da administração da empresa. É evidente que, o auditor é responsável somente em certificar a veracidade das informações repassadas por esse controle.

\section{Fraudes e Erros}

O termo "fraude" aplica-se a ato intencional de omissão e/ou manipulação de transações e operações, adulteração de documentos, registros, relatórios, informações e demonstrações contábeis, tanto em termos físicos quanto monetários (BRASIL, 2003).

Fraude, maneira em que o indivíduo apresenta ato intencional de se beneficiar ou favorecer outros, manipulando informações para burlar as leis internas e externas. As fraudes aparecem de diversas modalidades em uma organização, como a ocultação de ativos, alteração de documentos, modificação indevida de passivos e ativos, retirada de dinheiro de caixa, causando incalculáveis prejuízos ao patrimônio da entidade, assim como também da credibilidade dos trabalhos ou serviços prestados a terceiros (RODRIGUES, 2014).

O termo "erro" aplica-se a ato não-intencional de omissão, desatenção, desconhecimento ou má interpretação de fatos na elaboração de registros, informações e demonstrações contábeis, bem como de transações e operações da entidade, tanto em termos físicos quanto monetários (BRASIL, 2003).

Erros são atos cometidos por colaboradores ou administradores sem a intenção de prejudicar ou atrair para si ou para terceiros, vantagens. Não há a intenção de burlar leis e normas, são ações cometidas por desconhecimento, desatenção, mas que acabam prejudicando a entidade na elaboração das suas demonstrações contábeis (BATISTA et al., 2014).

A importância do cumprimento da ética e da moral pelos próprios gestores do negócio é tão importante, quanto à atitude ética e moral de cada funcionário da empresa. A prática de atitudes comportamentais corretas entre as duas classes evita mutuamente a ocorrência de ilícitos e erros na entidade. Dessa forma, contribuindo para o crescimento e fortalecimento da mesma.

\section{Auditoria Externa e Interna: Caracterização e Diferenciação}

A necessidade da auditoria externa surgiu pelo desenvolvimento do próprio sistema capitalista, empresas que antes eram pequenas, viram a necessidade de se modernizarem, 
inovando o local de trabalho, adaptando sistemas informatizados e transformando o seu escopo organizacional (SOUZA, 2015).

Os empresários viram que para fazer tantos investimentos era necessário obter recursos junto a terceiros. Diante disso, surgiu a necessidade de um profissional auditor que fosse totalmente independente para auditar as informações contábeis e emitir um parecer que trouxesse segurança junto aos investidores, pois esses investidores queriam ter segurança na empresa e nos dados que elas lhes forneciam, assim como também, se essa entidade teria a capacidade de obter lucros (ALMEIDA, 2007).

A auditoria externa ou auditoria independente é realizada por um profissional contador, bacharelado em ciências contábeis, com registro junto ao Concelho Federal de Contabilidade (CFC), e aprovado em concurso na Comissão de Valores Mobiliários (CVM). Dessa forma, essa atividade profissional é desempenhada atreves de normas de auditoria e técnicas contábeis determinadas por órgãos competentes para serem aplicadas no desempenho do trabalho (CREPALDI, 2004).

O profissional auditor externo ou independente tem sua visão focada além de apresentar a todos os stakeholders a situação em que se encontram as demonstrações contábeis e financeiras da organização, a situação do cumprimento das normas e legislações vigentes, pois seu interesse está voltado também para o bem coletivo (CREPALDI, 2004).

As práticas da auditoria independente se fizeram necessárias com a grande evolução do mercado, e para desempenhar uma função tão significativa foram adaptadas, exigências e atributos a esse profissional, como uma formação específica, leis e técnicas que ditassem as regras para a classe, garantindo uma maior segurança a todos.

Com a evolução dos negócios no Brasil, os empresários perceberam a importância de uma maior organização nos processos internos, dessa forma surgiu à auditoria interna como uma extensão da auditoria externa e também do contador. Para desempenha a função de auditor interno, não há a necessidade de uma formação específica. O seu surgimento se deu em razão do grande desenvolvimento empresarial e da necessidade de uma auditoria periódica dentro do conjunto organizacional, para verificação do cumprimento das normas internas e da eficiência dos departamentos funcionais da empresa, contribuindo para o crescimento do escopo organizacional (CREPALDI, 2004).

A auditoria interna exerce o seu trabalho, segundo as Normas Brasileiras de Contabilidade, a NBC TI 01, instituída pelo Conselho Federal de Contabilidade (CFC), através de ações no âmbito da entidade de maneira independente dos demais setores da organização, 
tendo como princípio prestar auxílio aos responsáveis pela alta gerência empresarial (BRASIL, 2016).

A ação da auditoria interna encontra-se organizada com características rigorosas e objetivas, com propósito de agregar valores ao trabalho da organização, apresentando auxílios para o desenvolvimento dos processos da administração e dos controles internos, indicando soluções para as informações colhidas e não fidedignas encontradas em sua análise.

As duas funções de auditoria são, de fato, muito semelhantes dentro da empresa, mas com algumas diferenças importantes. Ambas certificam a eficiência e eficácia do controle interno, dos registros contábeis, da veracidade desses dados e a aplicação de técnicas para verificação da fidedignidade dos dados, ou seja, toda técnica necessária é usada para apuração e certificação da credibilidade das informações colhidas dos departamentos auditados da entidade empresarial (SILVA; GODOY, 2016).

O auditor externo ou independente executa seu trabalho de auditoria dentro das corporações de forma totalmente independente, ou seja, não há nenhum vínculo empregatício com a instituição auditada, e as suas funções estão previstas em contrato e estabelecidas pela legislação específica. Diferentemente do auditor interno, que é um funcionário da entidade, às funções desempenhadas dentro da empresa é bem mais ampla. $\mathrm{O}$ auditor interno tem a sua tarefa definida pelo escopo gerencial, portanto, o seu trabalho é periódico (ALVES, 2015).

Serão apresentadas as diferenças básicas no quadro comparativo entre auditoria externa e interna:

Quadro 01 - Diferença entre auditoria externa e interna

\begin{tabular}{|c|c|c|}
\hline ELEMENTOS & AUDITORIA EXTERNA & AUDITORIA INTERNA \\
\hline Sujeito & Profissional independente & $\begin{array}{c}\text { Auditora interna } \\
\text { (funcionários da empresa) }\end{array}$ \\
\hline Ação e Objetivo & $\begin{array}{l}\text { Exame das demonstrações } \\
\text { Financeiras }\end{array}$ & Exame dos controles operacional \\
\hline Finalidade & $\begin{array}{c}\text { Opinar sobre as demonstrações } \\
\text { financeiras }\end{array}$ & $\begin{array}{c}\text { Promover melhoria nos controles } \\
\text { operacionais }\end{array}$ \\
\hline Relatório Principal & Parecer & $\begin{array}{c}\text { Recomendações de controle interno e } \\
\text { eficiências administrativas }\end{array}$ \\
\hline Grau de Independência & Mais amplo & Menos amplo \\
\hline Interessados no Trabalho & A empresa e o público em geral & A empresa \\
\hline Responsabilidade & Profissional, civil e criminal & Trabalhista \\
\hline $\begin{array}{l}\text { Número de áreas cobertas pelo } \\
\text { exame durante um período }\end{array}$ & Maior & Menor \\
\hline $\begin{array}{c}\text { Intensidade dos trabalhos em cada } \\
\text { área }\end{array}$ & Menor & Maior \\
\hline Continuidade do trabalho & Período & Contínuo \\
\hline
\end{tabular}

Fonte: Adaptado de Crepaldi e Crepaldi (2016) 


\section{Órgãos Relacionados ao Trabalho do Auditor}

Serão abordados os principais órgãos que regem a auditoria no Brasil, órgãos estes que são responsáveis pela criação de normas específicas para o trabalho desenvolvido pelos auditores no desempenho de suas funções nas organizações, são eles: Comissão de Valores Mobiliários (CVM), Instituto dos Auditores Independentes do Brasil (IBRACON), Conselho Federal de contabilidade (CFC), e o Instituto dos Auditores Internos do Brasil (AUDIBRA) (MAFFEI, 2017).

A Comissão de Valores Mobiliários (CVM) foi criada pela Lei ${ }^{\circ} 6.385$, de 07 de setembro de 1976, tem como o seu principal objetivo a fiscalização do mercado de capitais do Brasil, assim como também a criação de regras exercidas pelo auditor externo, e normas contábeis que devem ser desempenhadas pelas entidades. Dessa forma, para o auditor exercer a atividade no mercado mobiliário, deve estar devidamente registrado na Comissão de Valores Mobiliários (ALMEIDA, 2007).

O Instituto dos Auditores Independentes do Brasil foi criado em 13 de dezembro de 1971, esse instituto crio o seu próprio estatuto e por ele é regido, assim como também pelas leis vigentes no país, o Ibracon não tem nenhuma finalidade econômica e sua forma é federativa. Esse instituto atualmente trabalha em conjunto com o Conselho Federal de Contabilidade (CFC) na revisão e tradução das Normas Internacionais de auditoria emitida pela Federação Internacional de Contadores (IFAC) para que a partir dessa análise e aprovação pelo CFC, possa ser implantada do Brasil (SANTOS, 2015).

O Conselho Federal de Contabilidade (CFC) é uma pessoa jurídica de direito público. Criado pelo Decreto-Lei $n^{\circ}$ 9.295, de 27 de maio de 1946, esse conselho funciona como órgão fiscalizador que normatiza o exercício da classe contábil, assim como também orienta os profissionais contadores para que cumpra normas devidamente estabelecidas para a profissão de contabilista. O objetivo principal do CFC é o registro e a fiscalização do exercício da classe de contadores (RIBEIRO, 2017).

O Instituto dos Auditores Internos do Brasil foi criado em 20 de novembro de 1960, esse instituto é formado por uma sociedade civil com direito privado, sem nenhuma finalidade financeira. A Audibra se divide em três classes tintinas que são: a classe de membros efetivos, a classe de membros associados e a classe de membros honorários. É importante que os indivíduos tenham os atributos necessários para fazer parte de cada uma delas. Dessa forma é feito indicações desses profissionais pela diretoria com uma devida aprovação do conselho deliberativo (MENDES; SILVA, 2018). 


\section{Metodologia}

O presente estudo foi desenvolvido no município de Icó-Ceará, na qual envolveu uma pesquisa bibliográfica e transcorreu de agosto a outubro de 2018.

A mesma caracteriza-se por ser de natureza básica, com procedimentos em relação aos objetivos adotados do tipo exploratório. A pesquisa bibliográfica de natureza básica é desenvolvida a partir de materiais já elaborados e publicados, materiais esses que são constituídos principalmente de livros, artigos e revistas científicas, escritos e publicados por especialistas, e tem o intuito de levar o leitor a ter um contato direto com o raciocínio da investigação do problema (GIL, 2010).

Frente às definições contempladas para construção desse trabalho científico, utilizou-se de um levantamento de pesquisas acadêmicas sobre o tema abordado. A priori, se teve acesso a (47) trabalhos científicos por meio da base de dados ScIELO, contudo para utilidade do estudo aderiu-se apenas (17) artigos. Além destes foram utilizados (01) Dissertação (uma dissertação da UFRJ) e (3) Teses de Doutorado. Também foram adotados (3) livros sobre auditoria, publicados no período de 2004 a 2013. Todo material encontrado foi aplicado para o desenvolvimento desse trabalho acadêmico.

Para seleção das fontes, foram considerados os seguintes descritores de inclusão: a auditoria interna, fraudes e erros, e consequentemente a temática abordada, e os seguintes critérios de exclusão: artigos que fugiram da linha de pesquisa e artigos considerados repetidos em relação à temática.

Metodologicamente foi considerado o período de pesquisa 2014 a 2018, baseado em de pesquisa em site de revistas especializadas e na biblioteca Professor Paulo Petrola da Faculdade Vale do Salgado - FVS. Contudo, foram utilizadas também para construção desse trabalho, normas legislativas especificas.

\section{Resultados e Discurssões}

Os resultados obtidos nessa pesquisa se deram através do objetivo geral e dos objetivos específicos, onde foi possível esclarecer a importância da auditoria, a sua contribuição em iniciativas privadas e a diferenciação entre fraudes e erros no âmbito interno.

Com o desenvolvimento desta pesquisa, foi possível analisar importância do trabalho desempenhado pelo auditor interno dentro das organizações, gerando uma maior confiabilidade 
para o escopo organizacional. Mostrou-se a princípio a relação da contabilidade com a auditoria, para que dessa forma pudesse trazer o entendimento acerca do papel da auditoria e a classificação da auditoria externa e interna.

Para que fosse possível trazer um entendimento de forma mais clara sobre a auditoria interna e externa nas instituições privadas, retratando suas principais características, foram evidenciadas as singularidades entre as auditorias interna e externa em um quadro, facilitando esse entendimento de maneira objetiva, esclarecendo, a priori, os elementos, e em seguida, as diferenças entre ambas as auditorias. Cabe ressaltar que foi dada mais ênfase na auditoria interna, pois esse é o foco principal dessa pesquisa.

No tocante a responsabilidade do auditor na detecção de irregularidades, conforme ressalta Silva (2017) o auditor não é responsável pela detecção de fraudes e erros. Assim como complementa Justino e Silva (2016) a responsabilidade da detecção de ilícitos é de competência primaria dos gestores da entidade. Diante disso, não cabe ao auditor resolver, e sim, dar sua opinião de forma independente.

Já no que diz respeito à importância do auditor interno. De acordo com Silva, Lopes e Barbosa (2017) quanto Silva et al (2014) concordam que o auditor interno desempenha suas funções diminuindo os indicadores de ilícitos. Desse modo, se destaca a importância da auditoria no quesito de avaliar a situação da empresa para uma maior eficiência operacional e administrativa.

Conforme complementa Gomes (2015) o auditor interno trabalha para trazer conformidade das normas internas e proteção aos bens da entidade. Assim, no contexto atual em que se encontram as empresas, o auditor é visto como peça-chave e tem se tornado um instrumento indispensável para avaliar a eficiência dos gestores e zelar pela credibilidade das informações geradas.

Com relação às práticas de ilícitos, é necessário fazer uma distinção entre erros e fraudes cometidas no âmbito interno. Segundo Brasil (2003) e Batista et al (2014) os erros são atitudes involuntárias, que podem ser cometidas por colaboradores ou administradores sem a intenção de enganar ou atrair para si algum tipo de vantagem.

Diferentemente de erro, a fraude é uma ação ilícita, cometida com o intuito de causar dados à entidade e obter vantagens. Embora essas atitudes possam acontecer sobre os mesmos meios, como em documentos, registros contábeis, entre outros, as duas ações têm características totalmente diferentes que podem causar dados a entidades e impedi-la de alcançar seus objetivos de forma segura (RODRIGUES, 2014). 
Pelo que já foi supracitado, pode-se entender, então, que as diferenças entre fraudes e erros, é que: a fraude é uma pratica intencional, de má-fé, com o intuito de obter vantagens para benefícios próprios ou de terceiros, enquanto os erros são atitudes consideradas involuntárias, e não intencionais.

Segundo Crepaldi (2004) a auditoria contribui para o crescimento do escopo organizacional. Assim é visto que a contribuição da auditoria garante uma maior solidez da empresa e consequentemente abre portas para novos empregos. Conforme complementa Brasil (2016) o auditor contribui com a fiscalização dos controles, diminuindo a ocorrência de ilícitos. Dessa forma, contribui com a fiscalização dos controles e diminui a ocorrência de ilícitos.

Enfatizou-se também os órgãos que normatizam e fiscalizam a profissão dos auditores no Brasil, pois são eles quem estabelecem as diretrizes e normas a serem seguidas por esses profissionais. Tais normas contribuem para o aperfeiçoamento dos trabalhos desenvolvidos pelos auditores.

Pôde-se observar que o caminho traçado para obter as informações sobre o papel do auditor e sua importância dentro das organizações privadas foi alcançado. Vale ressaltar que a temática vai além do apresentado nesse trabalho, pois o trabalho do auditor conta com as participações de todos os departamentos da organização. Todas as funções e competências do auditor são a base para o trabalho ético e eficiente junto às organizações, ressaltando que essa foi a inspiração que foi proposta buscar na literatura.

\section{Considerações Finais}

Com o desenvolvimento desse trabalho científico e da temática abordada, assim como os dados colhidos e apresentados, foi possível obter informações importantes capazes de trazer o entendimento sobre o papel da auditoria interna na detecção de fraudes e erros em iniciativas privadas. Essa inspiração surgiu com o intuito de trazer mais informações relevantes acerca da temática para a sociedade, tendo como princípio responder os objetivos dessa pesquisa.

Dessa forma, foi possível compreender o surgimento da auditoria interna e o que levou essa profissão a ganhar tamanha importância dentro das organizações empresariais, assim como a sua imprescindibilidade e influência nas tomadas de decisões dos gestores. Contudo, foi possível entender o conceito da auditoria e a aplicação de técnicas capazes de fazer um filtro nas demonstrações da empresa, assim como entender a contribuição da contabilidade nas praticas da auditoria. 
A auditoria interna surgiu ganhando seu espaço ao longo dos anos no mercado, contribuindo para o alcance dos objetivos traçados pelos gestores. Esse profissional demonstra sua importância e contribuição em agregar valores de probidades através do seu trabalho de verificação dos dados da empresa. Entretanto, mesmo diante do trabalho desenvolvido por esse profissional, a empresa não fica isenta da ocorrência de possíveis fraudes ou erros, ficando claro também que esse profissional não é responsável primário na detecção de ilícitos.

Portanto, para evitar a ocorrência de ilícitos, cabe aos gestores investir cada vez mais na implantação de sistemas informatizados capazes de detectar a ocorrência de erros ou fraudes que prejudiquem o desenvolvimento da empresa, trabalhando sempre de forma preventiva, assim como colocando como princípio da sua empresa a ética e a moral, tanto para com os próprios gestores, como para os colaboradores. Essa visão deve fazer parte da história da empresa como sendo uma peça chave para o crescimento mútuo.

\section{Referências}

ALESSI, E. O pacote de medidas anticorrupção do ministério público federal e os direitos e garantias fundamentais. Raízes Jurídicas, v. 9, n. 1, p. 57-82, 2017.

ALMEIDA, M. C. Auditoria: um curso moderno e completo. 6 ed. São Paulo: Atlas, 2007.

ALVES, M. J. E. O papel da qualidade e auditoria interna na gestão de um município. 2015. Tese de Doutorado. Repositório Científico do Instituto Politécnico do Porto. Disponível: < http://recipp.ipp.pt/handle/10400.22/7778>. Acesso em: 25 Ago. 2018.

ALVES, L.; TIOSSI, F. M.; MILAN, W. W. Auditoria contábil interna: seu papel e relevância para as organizações. Organizações e Sociedade, v. 5, n. 3, p. 101-114, 2016.

ALVES, A. C. et al. Auditoria interna em uma empresa atacadista: um estudo de caso na percepção dos auditores e auditados quanto às práticas de auditoria interna. RAGC, v. 5, n. 18, 2017.

BATISTA, A. A. R. et al.. A importância da auditoria para a prevenção de erros e fraudes na organização. Diálogos em Contabilidade: Teoria e Prática, v. 2, n. 1, 2014.

BLANCH, T. F. Concentração do mercado de auditoria: o caso português. 2016. Tese de Doutorado. Repositório Científico do Instituto Politécnico do Porto. Disponível em: < https://repositorio.ipl.pt/handle/10400.21/7209>. Acesso em 22 Ago. 2018.

BRASIL. Conselho Federal de Contabilidade. Normas Brasileiras de Contabilidade: auditoria interna: NBC TI 01 e NBC PI 01. 2003. Disponível em: < 
http://www1.cfc.org.br/sisweb/sre/detalhes_sre.aspx?Codigo=2003/000986>. Acesso em 05 Set. 2018.

Conselho Federal de Contabilidade. Normas Brasileiras de Contabilidade: auditoria

interna: NBC TI 01 e NBC PI 01. 2016. Disponível em: < http://www1.cfc.org.br/sisweb/SRE/docs/RES_986.pdf>. Acesso em 10 Set. 2017.

CARVALHO, A. R.; VIEIRA, E. T. V. A Importância da Auditoria Interna e do Controle Interno, na Redução de Fraudes nas Instituições Financeiras. REPAE-Revista de Ensino e Pesquisa em Administração e Engenharia, v. 1, n. 2, p. 229-246, 2015.

CREPALDI, S. A. Auditoria contábil: teoria e prática. 3 ed. São Paulo: Atlas, 2004.

CREPAldi, S. A.; CREPAldI, G. S. Auditoria Contábil - Teoria e Prática. 10 ed. São Paulo: Atlas, 2016.

FREITAS, C. A. S. Auditoria de gestão e estratégia no setor público. Revista do Serviço Público, v. 52, n. 4, p. 57-70, 2014.

GABRIEL, R. J. O. Um estudo sobre a visão dos discentes de ciências contábeis, na região do médio sertão alagoano, no que se refere a atuação do contabilista a respeito da responsabilidade socioambiental empresarial. 2016. 54 f. Trabalho de Conclusão de Curso (Bacharelado em Ciências Contábeis) - Unidade Santana do Ipanema, Curso de Ciências Contábeis, Universidade Federal de Alagoas, Santana do Ipanema, 2018.

GIL, A. C. Como elaborar projetos de pesquisa. 5 ed. São Paulo: Atlas, 2010.

GOMES, Ana Paula. Aplicação da auditoria interna como ferramenta de melhoria de controles internos em uma empresa do setor de serviços de vigilância e monitoramento de Curitiba-PR. 2015.

JUSTINO, S. G.; SILVA, A. C. O controle interno aliado à auditoria interna para prevenir as fraudes e irregularidades nas empresas. ANAIS SIMPAC, v. 6, n. 1, 2016.

MAFFEI, J. L. G. CURSO DE AUDITORIA-Introdução à auditoria de acordo com as normas internacionais e melhores práticas. Editora Saraiva, 2017.

MENDES, J. J.; SILVA, K. N. A adoção da auditoria interna com foco no controle interno e na governança corporativa. Revista Saber Eletrônico, v. 2, n. 1, p. 28, 2018.

MOALLEM, D. Auditoria de demonstrações contábeis de grupos: estudo de caso sobre instruções da administração do grupo e de auditores. 2016.

MONTEIRO, R. P. Análise do sistema de controle interno no Brasil: objetivos, importância e barreiras para sua implantação. Revista Contemporânea de Contabilidade, v. 12, n. 25, p. 159-188, 2015.

RIBEIRO, J. M.; RIBEIRO, O. M. Auditoria fácil. Editora Saraiva, 2017. 
ROCHA, D. A. R. O contributo da auditoria interna na elaboração de boas práticas contabilísticas. Repositório Científico do Instituto Politécnico do Porto. 2016. Tese de Doutorado. Disponível em: < http://recipp.ipp.pt/handle/10400.22/9699>. Acesso em 23 Ago. 2018 .

RODRIGUES, S. M. F. S. O auditor interno e a gestão do risco empresarial. 2014. Tese de Doutorado. Instituto Politécnico do Porto. Instituto Superior de Contabilidade e Administração do Porto.

SANTOS, L. A. O impacto da adoção das IFRS nas demonstrações contábeis: Pesquisa do segmento de transportes aéreos das empresas listadas na BOVESPA. Novas Edições Acadêmicas, 2015.

SILVA, V. A. et al.. A profissão do auditor e o perito contábil na visão dos acadêmicos concluintes do curso de Ciências Contábeis de universidade pública e privada de Tangará da Serra/MT. Revista UNEMAT de Contabilidade, v. 3, n. 6, 2014.

SILVA, P. T. M.; GODOY, A. S. MBA-O que alunos e ex-alunos pensam a respeito do curso realizado, seu aprendizado, e do impacto em suas carreiras. Revista Gestão Universitária na América Latina-GUAL, v. 9, n. 3, p. 292-314, 2016.

SILVA, F. R.; LOPES, P. L.; BARBOSA, M. V. Capacitação profissional do auditor nas instituições de ensino e sua inserção no mercado. Revista Valore, v. 2, n. 1, p. 51-69, 2017.

SOUZA, I. C. D. Internacionalização das instituições de ensino superior: impactos no corpo técnico-administrativo da Universidade Federal do Rio de Janeiro. 2015. 143 f. Dissertação (mestrado em Administração) - Universidade do Grande Rio "Prof. José de Souza Herdy". Escola de Ciências Sociais Aplicadas, Rio de Janeiro, 2015.

Como citar este artigo (Formato ABNT):

FREITAS, Cliciana da Silva Correia; SENA, Ramon Amorim. O Papel da Auditoria Interna na Detecção de Fraudes e Erros em Iniciativas Privadas. Id on Line Rev.Mult. Psic., 2019, vol.13, n.43, p. 578-592. ISSN: 1981-1179.

Recebido: 22/11/2018;

Aceito: $23 / 11 / 2018$ 